\title{
Progressive Collapse Resistance of RC Frames under a Side Column Removal Scenario: The Mechanism Explained
}

\author{
Jian Hou ${ }^{1)}$, and Li Song ${ }^{2), *}$
}

(Received December 7, 2015, Accepted February 25, 2016, Published online March 11, 2016)

\begin{abstract}
Progressive collapse resistance of RC buildings can be analyzed by considering column loss scenarios. Using finite element analysis and a static test, the progressive collapse process of a RC frame under monotonic vertical displacement of a side column was investigated, simulating a column removal scenario. A single-story $1 / 3$ scale RC frame that comprises two spans and two bays was tested and computed, and downward displacement of a side column was placed until failure. Our study offers insight into the failure modes and progressive collapse behavior of a RC frame. It has been noted that the damage of structural members (beams and slabs) occurs only in the bay where the removal side column is located. Greater catenary action and tensile membrane action are mobilized in the frame beams and slabs, respectively, at large deformations, but they mainly happen in the direction where the frame beams and slabs are laterally restrained. Based on the experimental and computational results, the mechanism of progressive collapse resistance of RC frames at different stages was discussed further. With large deformations, a simplified calculation method for catenary action and tensile membrane action is proposed.
\end{abstract}

Keywords: progressive collapse, RC frame structures, catenary action, tensile membrane action.

\section{Introduction}

The situation in which there is local failure of a primary structural component that leads to the collapse of adjoining members is called progressive collapse, and this, in turn, leads to total collapse or the collapse of a disproportionately large part of the affected structure (ASCE 2010). Various buildings throughout the world have gone through partial or total progressive collapse throughout the past several decades. These collapses have resulted from gas explosion, terror attack, and other factors. These progressive collapse accidents resulted in significant property loss and casualties. The engineering community has therefore paid greater attention to the situations of buildings subjected to damage from abnormal events. New codes and standards for development have been considered by public regulatory agencies. Implicit resistance to progressive collapse is achieved by maintaining the integrity and ductility of the structure and explicit resistance is achieved by providing alternate load paths so that local damage is absorbed by the structure to avert major collapse (GSA 2013; DoD 2009).

\footnotetext{
${ }^{1)}$ Department of Civil Engineering, Xi'an Jiaotong University, Xi'an 710049, People's Republic of China.

${ }^{2)}$ School of Civil Engineering, Central South University, Changsha 410075, People's Republic of China.

*Corresponding Author; E-mail: songlisong_2002@163.com Copyright (C) The Author(s) 2016. This article is published with open access at Springerlink.com
}

Design codes and guidelines currently in place are not considered to completely satisfy the requirements for progressive collapse design. Also, to obtain a better understanding of the mechanisms of progressive collapse resistance of structures, further research is necessary. Seeking the establishment of rational methods to assess structural robustness under extreme accidental events is the ultimate goal. Many efforts have been made recently to carry out research on the behavior of building structures with the loss of a column. Much attention has been given to the behavior of beams that bridge over removed column areas, which are under amplified gravity loads in beam-column substructures or planar frames (Sadek et al. 2011; Mehrdad et al. 2011; Choi and Kim 2011; Su et al. 2009; Yi et al. 2008; Hou and Yang 2014; Kim and Choi 2015; Kang et al. 2015). It was concluded that a generous reserve capacity of the catenary action in beams that carry the gravity loads in a tension mode is necessary for mitigating progressive collapse. For different seismic fortification intensities, it was noted that the load versus displacement curves exhibited similar characteristics, and the more stringent seismic design and detailing increased the failure displacement and the ultimate load. There have been reports of studies that have analyzed progressive collapse behavior of RC frames or beam-slab substructures by experiments or numerical analyses (Mehrdad et al. 2007; Pham and Tan 2013a, b; Pachenari and Keramati 2014; Qian et al. 2015). It was found that tensile membrane actions in slabs that inevitably develop in large deformation stage play a key role in its collapse resistance. In order to reduce the computational costs of the conventional finite element methods, some researchers (Brunesi and Nascimbene 2014) 
have presented an open access procedure using a fiber-based model for large scale nonlinear transient dynamic analysis of three-dimensional frames. Málaga-Chuquitaype et al. (2016) have examined the contribution of secondary frames to the mitigation of collapse in steel buildings, which provides the reference for RC buildings. Based on Monte Carlo simulation, Brunesi et al. (2015) have developed a framework for progressive collapse fragility analysis of RC frames, in which the random properties of materials, geometrical parameters et al. can be considered. However, experimental and computational study on the progressive collapse of space RC frames is currently inadequate, and no reasonable or simplified mechanism and calculation method for the progressive collapse resistance of space RC frame structures has yet been developed.

Here we report the results from a computational and experimental study that investigated the static responses of a $\mathrm{RC}$ frame that had side column loss. We also evaluated the effect of both tensile membrane action in the frame slabs and catenary action in the frame beams to assess the progressive collapse resistance of structures. A one-third scale structure was designed, built and tested. To get more detailed structural information during the progressive collapse, a nonlinear numerical analysis was conducted using the LSDYNA finite element software (Hallquist 2007). Based on experimental and computational results, the mechanism of progressive collapse resistance of $\mathrm{RC}$ frames at different stages is discussed further. With large deformations, a simplified calculation method for catenary action and tensile membrane action are proposed.

\section{Experimental Program and Finite Element Modeling}

\subsection{Experimental Program}

One of the most critical internal column loss scenarios is loss of a penultimate-external column on the ground floor of a structure. First, with lack of external lateral supports, the development of catenary action in beams and tensile membrane action in slabs relies solely on the perimeter columns and the perimeter compressive ring formed within the deflected slabs, as illustrated in Fig. 1a. Secondly, with large deformations, it is possible that the sum of catenary forces and tensile membrane forces may pull the perimeter columns at the ground floor inwards, triggering a progressive collapse, as shown in Fig. 1b. Therefore, this research focused on the behavior of a two-span, two-bay, single-story RC frame subjected to side column loss.

A four-span, eight-story and four-bay RC frame structure was designed considering the concrete design code and seismic design code of China (GB50010-2010 2010; GB50011-2010 2010). It should be noted that the Chinese code is generally similar to Eurocode 2 although the load and resistance factors are slightly different. It is expected that a building designed in accordance with Eurocode 2 will possess a marginally higher factor of safety given the differences in load and resistance factors between the two

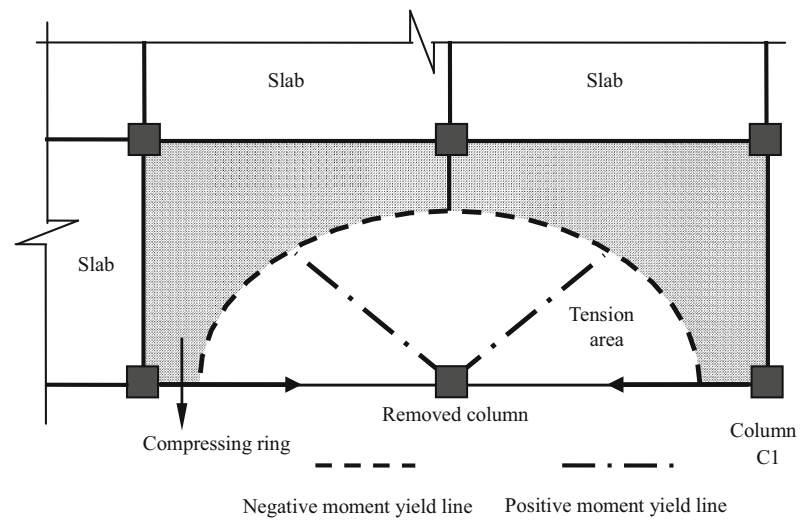

(a)

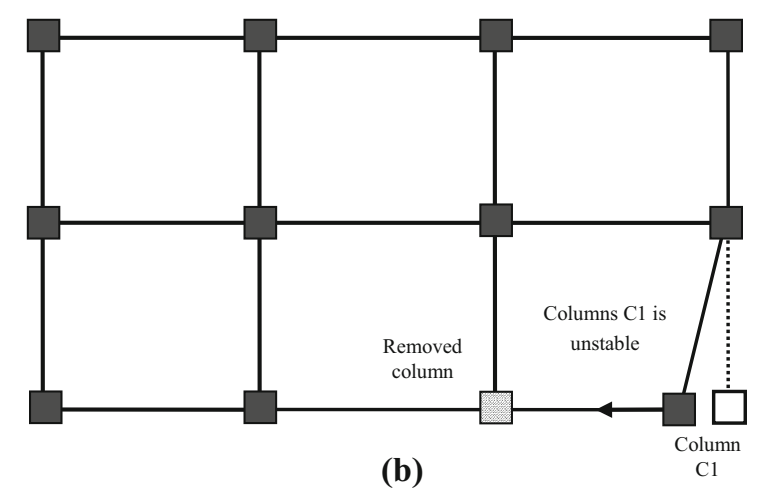

Fig. 1 Structures subjected to a penultimate-external column loss. a Self-equilibrium stage. b Possible failure mode.

codes. Table 1 summarizes the details of the prototype frame. A one-third scale model of a segment of the ground story of the original frame was made to be used in the collapse experiments. The floor height of the model frame was $1100 \mathrm{~mm}$. The floor plan details of the reinforcement and cross-sectional dimensions that were used in the model frame are shown in Fig. 2. The middle column on the A-axis, namely, the side column of the model frame was removed when the model was built in the laboratory, but the corresponding frame joint was intact. In fact, the support of the removed side column were considered, namely, the prototype frame was intact when it was designed according to design codes.

Yi et al. (2008) constructed a middle column of a planar frame by stacking two mechanical jacks and a load cell, and investigated the structural response before and after the middle column was removed. In the initial stage of the experiment, we applied a constant vertical load to the top of the removed column area and the model load was achieved by the unloading of the mechanical jacks. In our experiment, no constant load was placed on the top of the area where the column was removed at the beginning of the experiment. The step-by-step loading process was initiated by a MTS servo actuator on the top of the removed side column. In fact, the results of the two kinds of loading mode are almost equivalent, but the latter is less complicated. Therefore, the second loading mode was adopted in the literature (Sadek et al. 2011) and our experiment. Actually, a static experimental progressive collapse evaluation is presented in the 
Table 1 Details of prototype frame.

\begin{tabular}{|c|c|c|c|c|c|c|c|c|}
\hline \multirow[t]{4}{*}{ Items } & \multirow[t]{2}{*}{ Floor height } & \multirow[t]{2}{*}{ Bay span } & \multirow[t]{2}{*}{ Depth span } & \multirow{2}{*}{\multicolumn{2}{|c|}{\begin{tabular}{c|} 
Beam size \\
Depth \\
\end{tabular}}} & \multicolumn{3}{|c|}{ Column size } \\
\hline & & & & & & Width & Depth & Width \\
\hline & \multirow[t]{2}{*}{$3300 \mathrm{~mm}$} & \multirow[t]{2}{*}{$3900 \mathrm{~mm}$} & \multirow[t]{2}{*}{$5400 \mathrm{~mm}$} & Bay direction & Depth direction & & & \\
\hline & & & & $350 \mathrm{~mm}$ & $450 \mathrm{~mm}$ & $200 \mathrm{~mm}$ & $400 \mathrm{~mm}$ & $400 \mathrm{~mm}$ \\
\hline \multirow[t]{3}{*}{ Items } & \multicolumn{2}{|c|}{ Floor loads } & \multicolumn{2}{|c|}{ Seismic fortification intensity } & & \multicolumn{2}{|c|}{ Materials } & \\
\hline & $\begin{array}{l}\text { Live (other/ } \\
\text { roof) }\end{array}$ & $\begin{array}{l}\text { Constant } \\
\text { (other/roof) }\end{array}$ & \multirow{2}{*}{\multicolumn{2}{|c|}{7}} & Concrete & \multicolumn{2}{|c|}{ Longitudinal steel bars } & Stirrups \\
\hline & $2.5 / 0.5 \mathrm{kN} / \mathrm{m}^{2}$ & $6.0 / 7.5 \mathrm{kN} / \mathrm{m}^{2}$ & & & $\mathrm{C} 30$ & \multicolumn{2}{|c|}{ HRB335 } & HPB300 \\
\hline
\end{tabular}

C30 of concrete strength grade denote the characteristic value of compression strength for cube dimensions of $150 \times 150 \times 150 \mathrm{~mm}$ is $30 \mathrm{MPa}(1 \mathrm{MPa}=0.145 \mathrm{ksi})$. HRB335 of steel bar types denote the characteristic value of strength for hot-rolled ribbed steel bar is $335 \mathrm{MPa}$; HPB300 of steel bar types denote the characteristic value of strength for hot-rolled plain steel bar is $300 \mathrm{MPa}$.

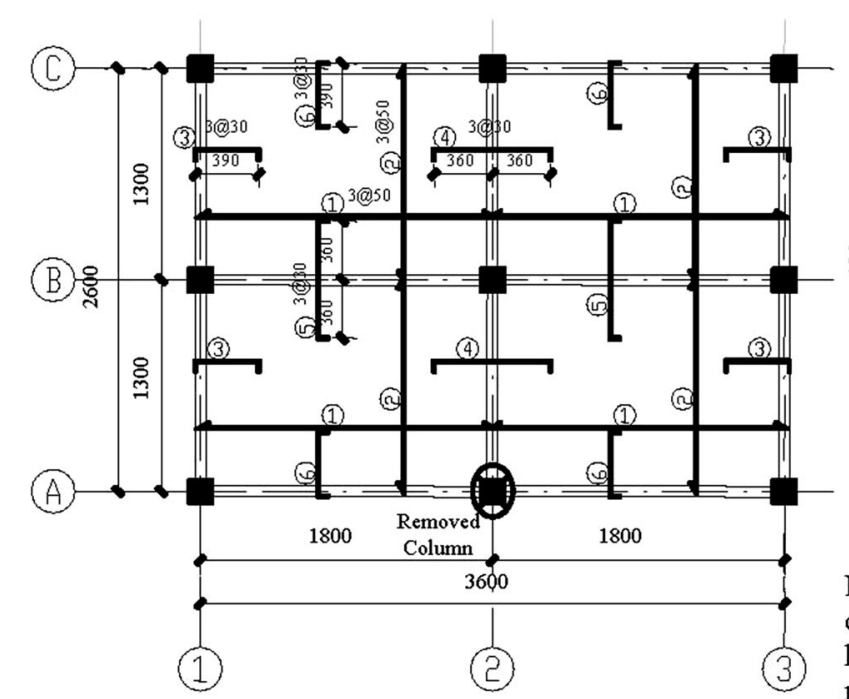

(a) Plan of model frame and details of slab reinforcement (slab thickness $30 \mathrm{~mm}$ )

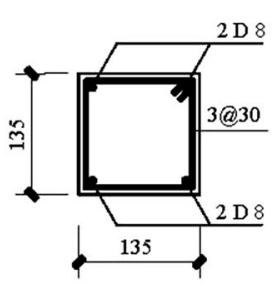

(b) Column section

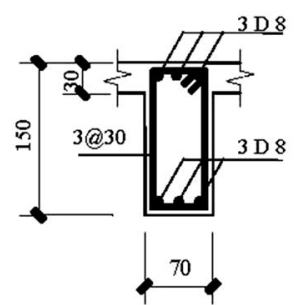

(c) A, B, C axes

beam section

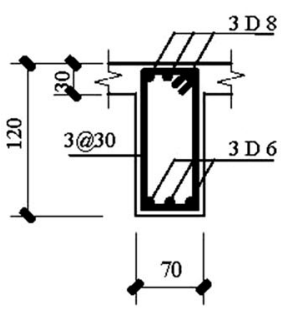

(d) $1,2,3$ axes

beam section

Note: Spacing of stirrups is $15 \mathrm{~mm}$ in beam and column ends, the critical regions are $200 \mathrm{~mm}$ in transverse beam ends, $300 \mathrm{~mm}$ in longitudinal beam and column ends; all longitudinal reinforcements (top and bottom) in frame beams are fully anchored in the joints of frame.

Fig. 2 Details of model frame (unit: $\mathrm{mm}$ ). a Plan of model frame and details of slab reinforcement (slab thickness $30 \mathrm{~mm}$ ). b Column section. c A, B, C axes beam section. d 1, 2, 3 axes beam section. Note Spacing of stirrups is $15 \mathrm{~mm}$ in beam and column ends, the critical regions are $200 \mathrm{~mm}$ in transverse beam ends, $300 \mathrm{~mm}$ in longitudinal beam and column ends; all longitudinal reinforcements (top and bottom) in frame beams are fully anchored in the joints of frame.

paper. However, a typical building structure exhibits a highly nonlinear dynamic response under a sudden column loss scenario. Based on the energy conservation principle, Izzuddin et al. (2008) proposed a simplified method by which the simplified dynamic response and progressive collapse resistance can be derived from the static progressive collapse response.

Figure 3 depicts the details of the instrumentation layout and test setup. The load was placed on the top of the area of the removed side column with a MTS servo actuator, as shown in Fig. 3. A rate of $3 \mathrm{~mm} / \mathrm{min}$ was used to apply the load under displacement control. Vertical and horizontal displacement transducers and steel stain gauges were used in the model frame test. Downward displacements of the top of the removed side column were imposed until failure. Frame collapse is defined in this study as the rupture of tension steel bars in the floor beams; in fact, the progressive collapseresistance capacity reached the peak at the same time.

\subsection{Finite Element Modeling}

Due to the limitations of experimental conditions and cost, the structural response information obtained in the experiment was not enough. A computational study of the response of the structural progressive collapse described in this paper was carried out using explicit time integration in LS-DYNA. Both geometrical and material nonlinearities were accounted for in the analysis and this included fracture with element erosion. Concrete was represented in the model by finely meshed solid elements, and beam elements represented reinforcing bars. The reinforcing bar steel properties were modeled with a piecewise-linear plasticity model (Material 24 in LS-DYNA) and stress-strain curves were based on the tensile test data. The measured values of mechanical properties of steel bars and concrete are shown in Table 2. The engineering stress-strain curves, however, were transformed into true stress-strain curves. A continuous surface cap model was used for the concrete material (Material 159 in 


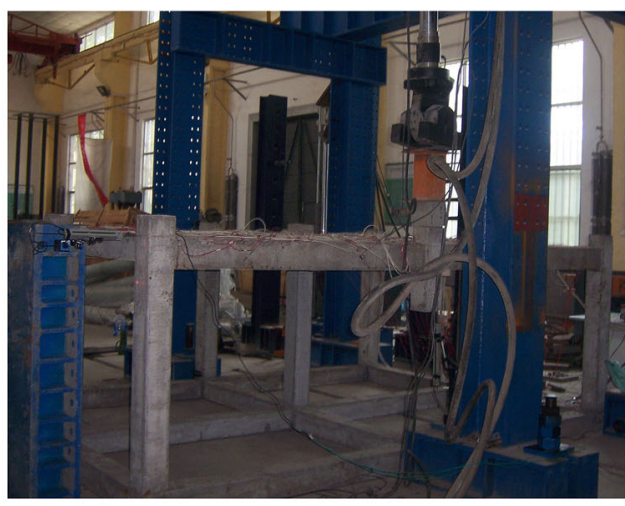

(a)

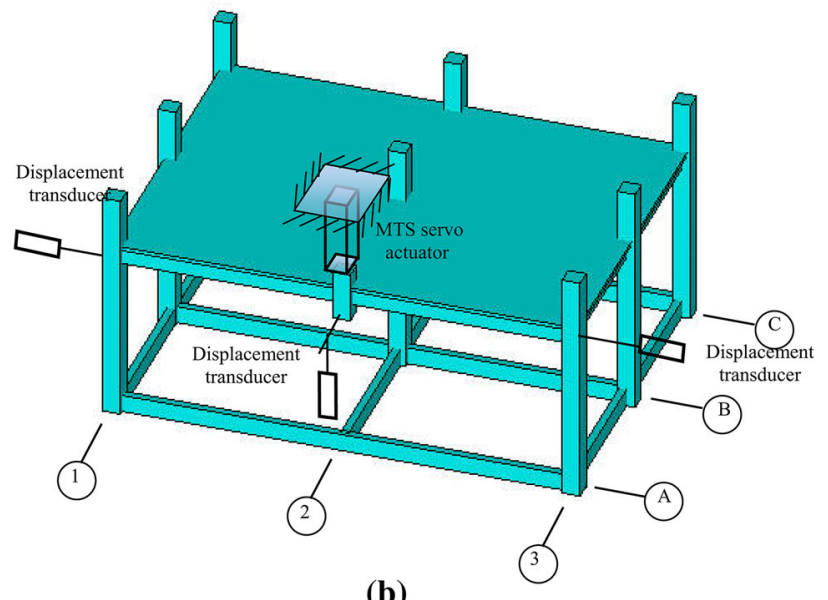

(b)

Fig. 3 Test setup and instrumentation layout. a Photograph. b Schematic diagram.

LS-DYNA). Our model captured the dominant characteristics of concrete responses, including softening caused by damage accumulation and confinement effects. Element erosion was used to model fractures, with the values for erosion strain for an element size calibrated to the failure strain values from the tensile tests. Solid elements were not eroded in this study to avoid excessive loss of stiffness. Since this study focus on the resistance of the whole structure rather than the simulation of cracking, cracks are not modeled explicitly in order to simplify the model and reduce the computational cost. But concrete cracking can be reflected by contours of the damage index computed by the concrete material model. The bottom of all columns except the removal side column was assumed to be fixed. In the computational study, the loading mode was the same as the experiment. Due to the symmetry, only one-half of the whole model was established in the computation, and the overview of the model is shown in Fig. 4.

Defining a one-dimensional contact interface (Contact_1d in LS-DYNA) was used to model bond-slip behavior between the solid elements that represented concrete as well as the beam elements that represented reinforcing bars. Two sets of nodes were required to define the contact, with the concrete nodes specified as master nodes and the reinforcement nodes specified as slave nodes. The parameters of the bond-slip model were selected with reference (Shi and Li 2009). Bond slip was not considered for column longitudinal and transverse reinforcement. The beam elements that represented the reinforcing bars were constrained to be within the solid elements with the CONSTRAINED_LAGRANCE_IN_SOLID card.

\section{Analysis of Progressive Collapse Process}

Figure 5 illustrates the plot of the vertical displacement of the removed column and the vertical load. Figure 5 shows that the vertical load gradually increased as the vertical displacement of the removed column increased. Figure 6 shows the failure pattern of the frame model. It is noted that the progressive collapse of the structure occurs only in the area adjacent to the removed column, namely, the area between A-axis and B-axis. The following description about failure phenomenon of frame beams and slabs is located in this area.

Figures 7 and 8, which are derived from the finite element analysis results, show the longitudinal reinforcement stress at frame beam ends near the removed column and the slab bottom reinforcement stress in a longitudinal direction. Based on the characteristics of the force-displacement relationship, the reinforcement stresses and structural behaviors, the progressive collapse process of the structure may be divided into four stages: the elastic stage, the elastoplastic stage, the plastic stage and the composite stage of catenary action and tensile membrane action.

\subsection{Elastic Stage}

As show in Fig. 5, Section OA can be considered as the elastic stage with cracking of frame beams observed at State

Table 2 Properties of steel bars and concrete.

\begin{tabular}{|c|c|c|c|c|c|c|c|}
\hline \multicolumn{2}{|c|}{ Material } & \multirow{2}{*}{$\begin{array}{c}\begin{array}{c}\text { Diameter } \\
\text { measurement, } \\
\mathrm{mm}\end{array} \\
8.0\end{array}$} & \multirow{2}{*}{$\begin{array}{c}\begin{array}{c}\text { Young's } \\
\text { modulus, MPa }\end{array} \\
2.0 \times 10^{5}\end{array}$} & \multirow{2}{*}{$\begin{array}{c}\begin{array}{c}\text { Yield strength, } \\
\mathrm{MPa}\end{array} \\
347.0\end{array}$} & \multirow{2}{*}{$\begin{array}{c}\text { Ultimate } \\
\text { strength, MPa } \\
488.6\end{array}$} & \multicolumn{2}{|c|}{ Rupture strain, $\delta_{10}$} \\
\hline Steel bars & $\Phi 8$ & & & & & $\begin{array}{c}\text { Necking zone } \\
25.3 \%\end{array}$ & \begin{tabular}{|c|}
$\begin{array}{c}\text { Outside necking } \\
\text { zone }\end{array}$ \\
$16.1 \%$
\end{tabular} \\
\hline & $\Phi 6$ & 6.4 & $2.0 \times 10^{5}$ & 283.2 & 443.8 & $31.0 \%$ & $20.6 \%$ \\
\hline & Ф 3 & 3.5 & / & 331.0 & 387.6 & 1 & / \\
\hline & \multicolumn{3}{|c|}{ Young's modulus, MPa } & \multicolumn{4}{|c|}{ Compression strength of concrete prism, $\mathrm{MPa}$} \\
\hline Concrete & \multicolumn{3}{|c|}{$3.05 \times 10^{5}$} & \multicolumn{4}{|c|}{36.8} \\
\hline
\end{tabular}




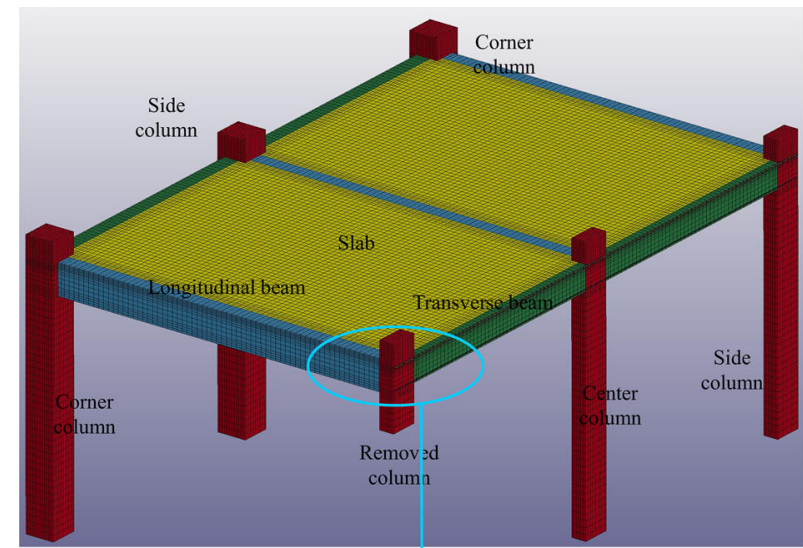

(a)

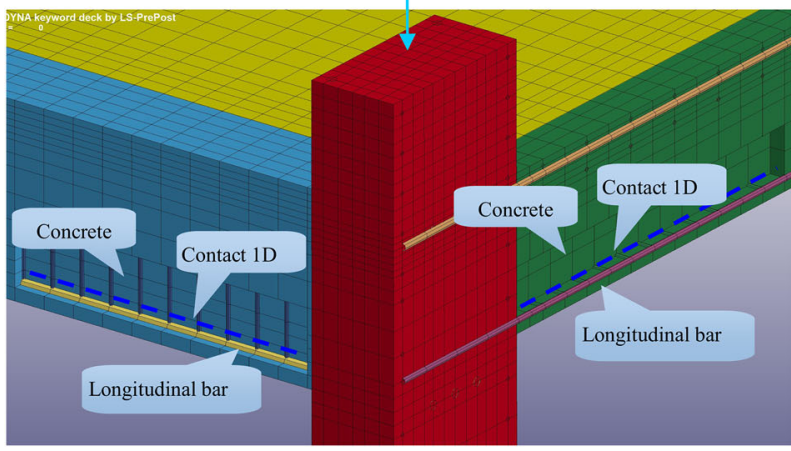

(b)

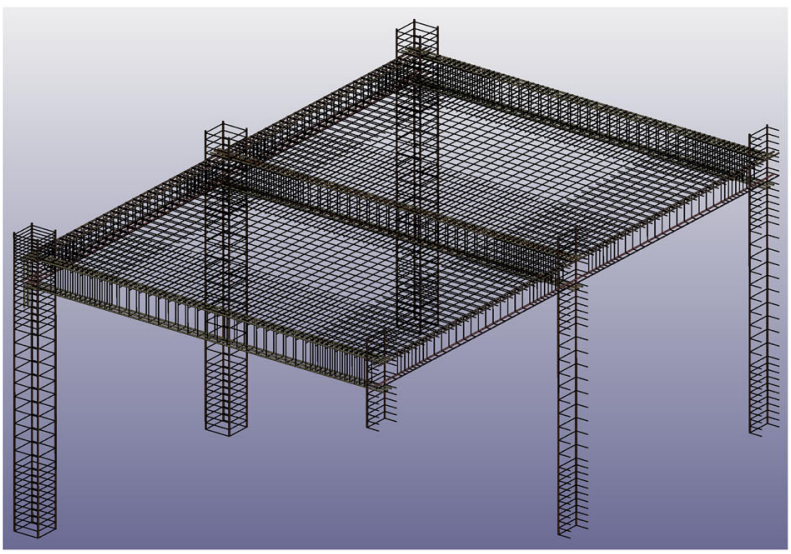

(c)

Fig. 4 Finite element 1/2 model of the experimental model frame. a Mesh of concrete. b Diagram of Contact 1D. c Mesh of reinforcing bars

A, and the displacement of the removed column was less than $5 \mathrm{~mm}$ in this stage. It can be seen from Fig. 7 that the bottom reinforcement was in tension and the stress was almost linearly increased with increases in the vertical displacement of the removed column in the longitudinal and transverse beams at this stage. However, the values of the stress were lower than the corresponding yield values. The top reinforcement was in compression and the stress was very small in the longitudinal and transverse beams at this stage. As shown in Fig. 8, the stress of the slab bottom reinforcement was very small at this stage. The above

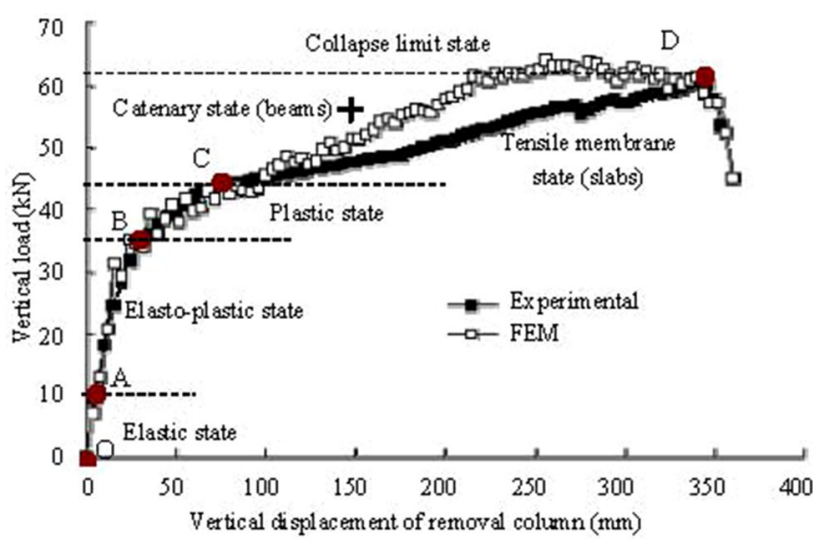

Fig. 5 Vertical load versus downward displacement of removal column.

analysis indicated that the frame beams and slabs were almost in the elastic state.

\subsection{Elastoplastic Stage}

In Fig. 5, Section AB is the elastoplastic stage, and the displacement of the removed column was about $28 \mathrm{~mm}$ at State B. In this stage, the vertical load no longer increased linearly with increasing vertical displacement of the removed column. As shown in Fig. 7, the bottom reinforcement had entered the yield state in this stage. From the stress of the slab bottom reinforcement, it was found that the stress of a part of the reinforcement near the removed column obviously increased with increases in the vertical displacement of the removed column, but the stress of the others far from the removed column was still very small at this stage. Based on the experimental observation, it was found that the concrete of frame slabs had obviously cracked, and plastic hinges in the frame beam ends near the removed column had formed in this stage.

\subsection{Plastic Stage}

In Fig. 5, Section BC is the plastic stage, and the displacement of the removed column was about $68 \mathrm{~mm}$ at State C. displacement of the column that was removed was approximately $68 \mathrm{~mm}$ in State C. The increasing rate of the vertical load in this stage with increasing vertical displacement of the removed column decreased significantly, and the deformations were dominated by plastic rotations of the frame beams. From the longitudinal reinforcement stress at the frame beam ends near the removed column, it was observed that the top reinforcement changed to tension from compression in the longitudinal beams in this stage. However, due to the lack of lateral support or constraint, the top reinforcement in the transverse beam was still under the compression state at this stage. As shown in Fig. 8, the stress of a part of the reinforcement near the removed column significantly increased with increases in the vertical displacement of the removed column, and the maximum of the stress had exceeded $200 \mathrm{MPa}$. However, the greater the distance from the removed column, the smaller the stress became. 


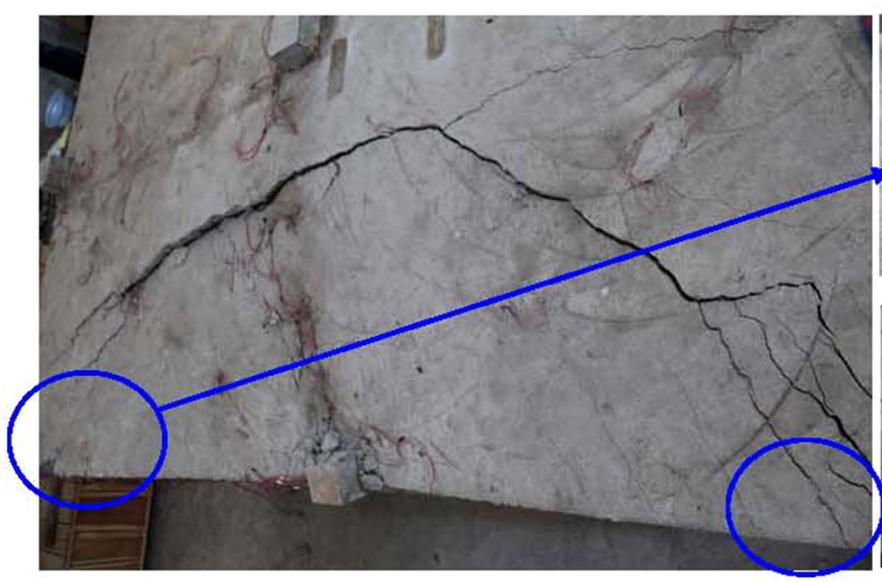

(a) Experiment (other beam ends see following text)

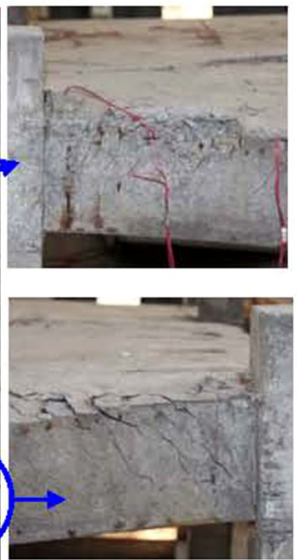

Front view

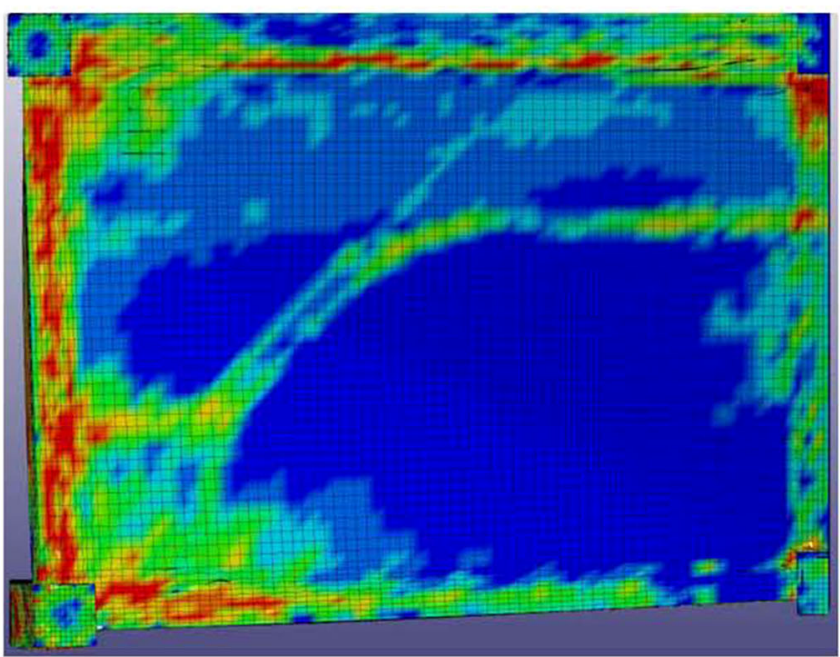

(b) FEM (Local model)

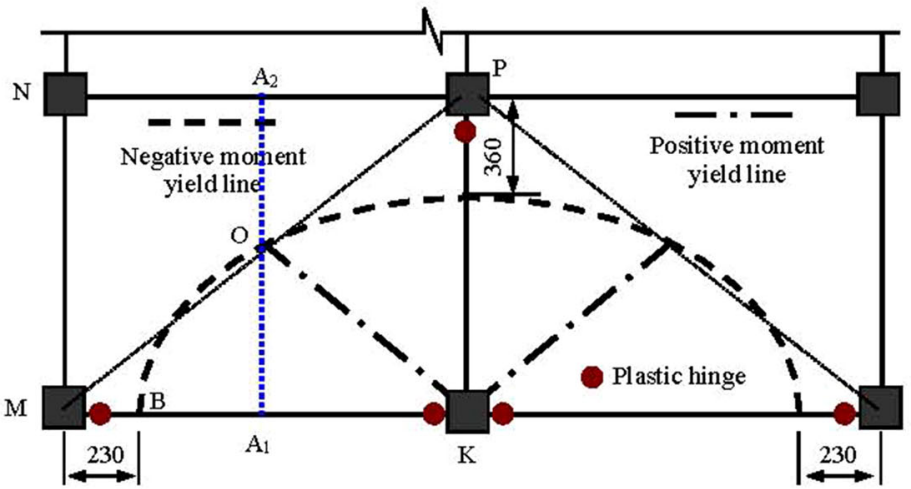

(c) Schematic diagram

Fig. 6 Failure pattern of frame model (unit: $\mathrm{mm}$ ). a Experiment (other beam ends see following text). b FEM (local model). c Schematic diagram.

\subsection{Composite Stage of Catenary and Tensile Membrane}

In Fig. 5, Section CD is the composite stage of thecatenary and tensile membrane. After the plastic stage Section BC, it can be observed that the tension cracks in concrete penetrated through the compression zones in frame beams and slabs in the experiment, which indicated the moments of resistance at the plastic hinges in the frame beams and the plastic hinge lines in the frame slabs can be ignored at this stage. Figure 7 shows that the bottom longitudinal reinforcement in the longitudinal frame beams had entered the strain-hardening range, and the top longitudinal reinforcement in the longitudinal frame beams was fully in tension at this stage and had entered the yield state at State D. However, in the transverse frame beam and the transverse direction of the frame slabs, due to the lack of lateral support or constraint, the beam and slabs worked approximately as a cantilever beam and slabs. Therefore, at this stage, the transverse frame beam and transverse direction of the frame slabs almost entirely failed, as shown in Fig. 9. Figure $7 \mathrm{~b}$ 


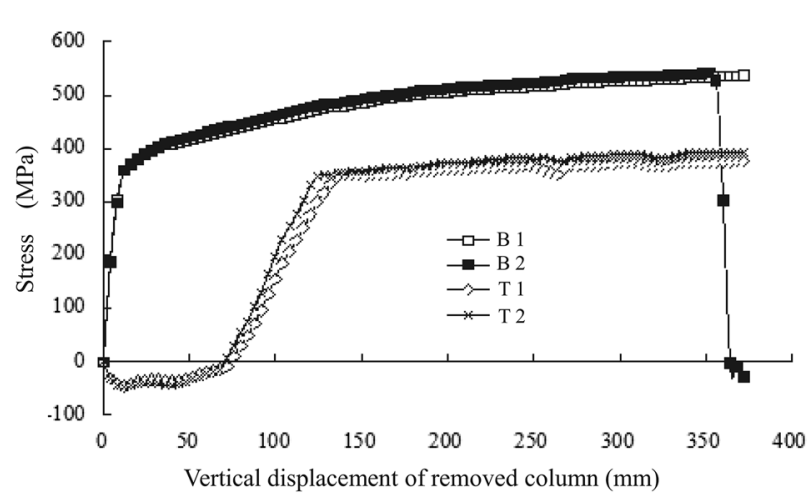

(a)

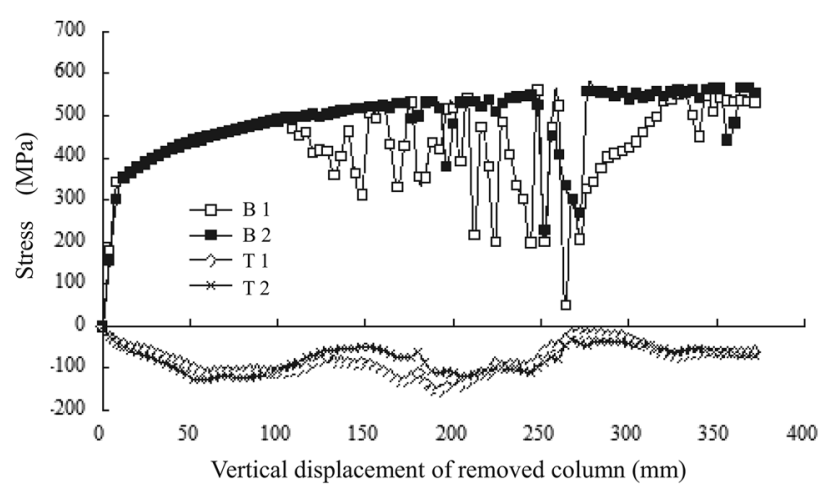

(b)

Fig. 7 Longitudinal reinforcement stress at beam ends near removed column ( $B$ bottom reinforcement; $T$ top reinforcement). a Longitudinal beams. b Transverse beams.

shows that the top reinforcement in the transverse beam was still under the compression state and the stress fluctuated obviously at this stage. Also, after the displacement of the removed column more than $100 \mathrm{~mm}$, the tensile stress of the bottom reinforcement in the transverse beam was not reliable. A similar phenomenon was found in the transverse direction of the frame slabs. The above analysis indicated that the catenary mechanism and the tensile membrane mechanism can only be formed in the longitudinal frame beams and the longitudinal direction of frame slabs, respectively. Figure 8 shows that a part of the longitudinal reinforcement near the removed column had entered the yield state at State D. At State D, the structure attained a maximum vertical load of $60.7 \mathrm{kN}$ at a vertical displacement of $345 \mathrm{~mm}$, at which point one of the bottom steel bars of frame beams adjacent to the removed column on A-axis ruptured, as shown in Fig. 10. The experimental observation was consistent with the numerical analysis results, as shown in Fig. 7.

\section{Progressive Collapse Resistance Mechanism}

$\mathrm{RC}$ frame structure behavior should be in accord with the seismic principle of strong-column-weak-beam. Negative bending moment regions on both sides of a column that is to

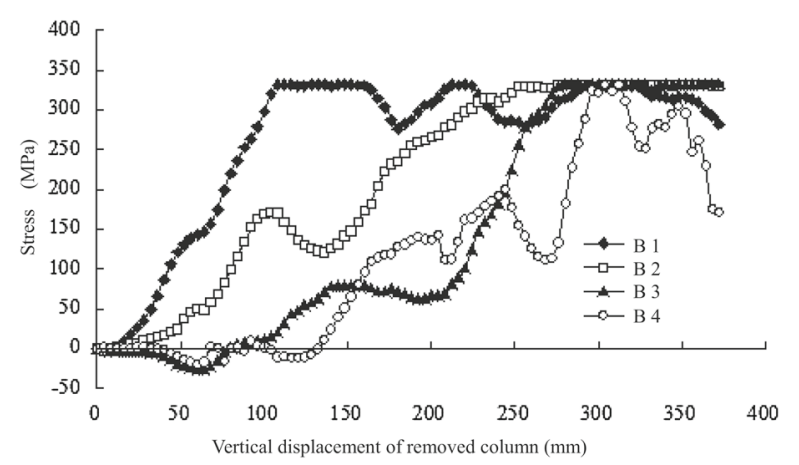

(a)

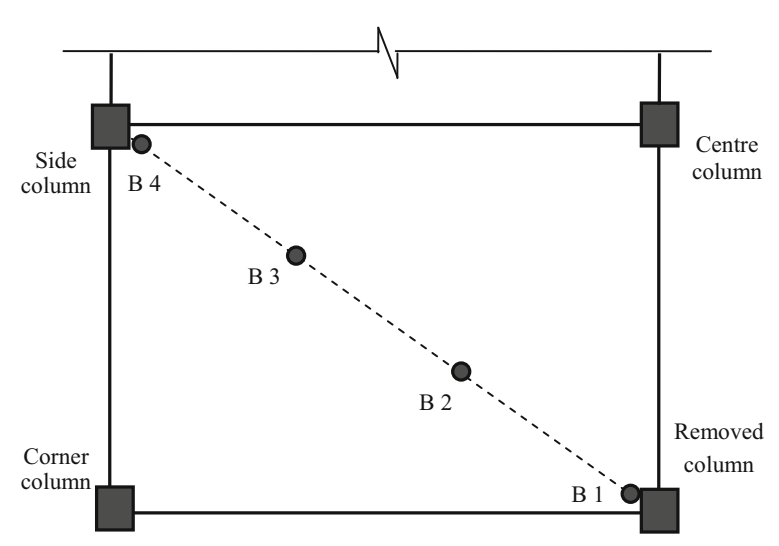

(b)

Fig. 8 Slab bottom reinforcement stress in longitudinal direction. a Reinforcement stress.b Location of stress

be removed are missing, however, these locations have maximum positive bending moment after removed column loss, and the spans of beams and slabs became larger, as shown in Fig. 11. This indicated that after a load-bearing column is removed, the beams that were connected to this column must transfer the load previously borne by the column and bridge over the damaged area. Thus, it was observed that columns were much stronger, and they may have a negligible effect on progressive collapse resistance compared to other elements in the system. The catenary mechanism of the beams and the tensile membrane mechanism of the slabs combine to resist vertical loads in the progressive collapse limit state.

\subsection{Catenary Mechanism of Beams}

Figure 6 shows the failure pattern of the frame model. Due to the entire failure of the transverse frame beam and the transverse direction of the frame slabs in the failure zone, the effect of the transverse beam and the transverse direction of the slabs can be ignored, while calculating the progressive collapse resistance of the whole structure at a collapse limit state.

Based on the experimental observation, it can be found that the axes of the longitudinal frame beams are almost still straight at the collapse limit state. Figure 12 shows the vertical displacement of different positions on the longitudinal frame beams at the collapse limit state, which is 


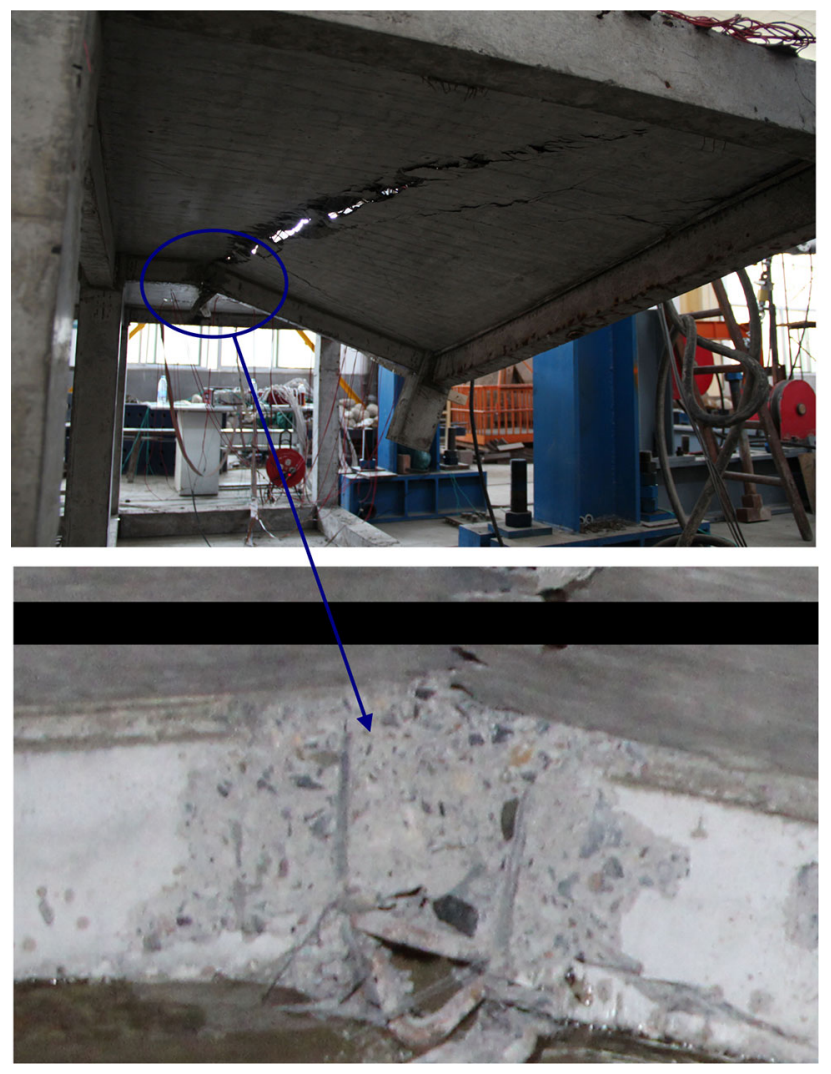

Fig. 9 Failure of frame beam and slabs in short axis direction at collapse limit state.

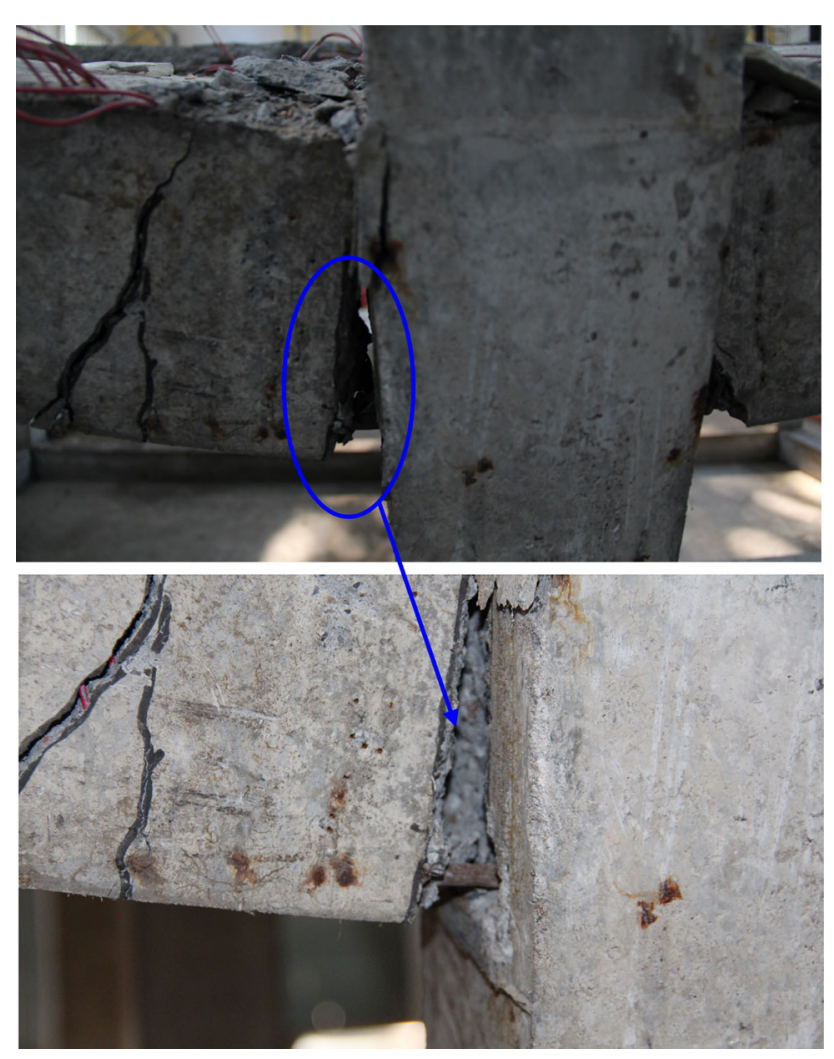

Fig. 10 Rupture of steel bar in A-axis frame beam.

obtained from the numerical results and is consistent with the experimental observation. Therefore, the model of the progressive collapse resistance of $\mathrm{RC}$ beams can be

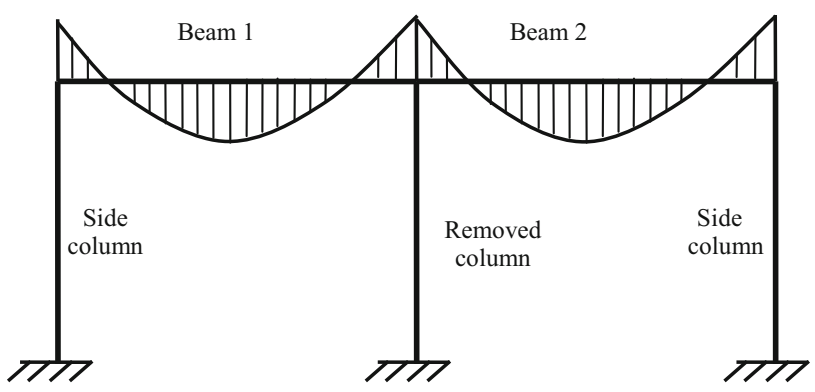

(a)

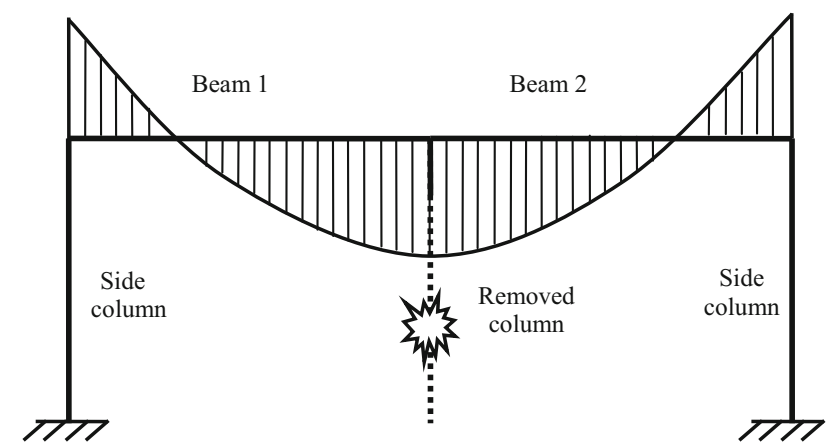

(b)

Fig. 11 Schematic diagram of bending moment distribution of beams. a Before removed column missing. b After removed column missing.

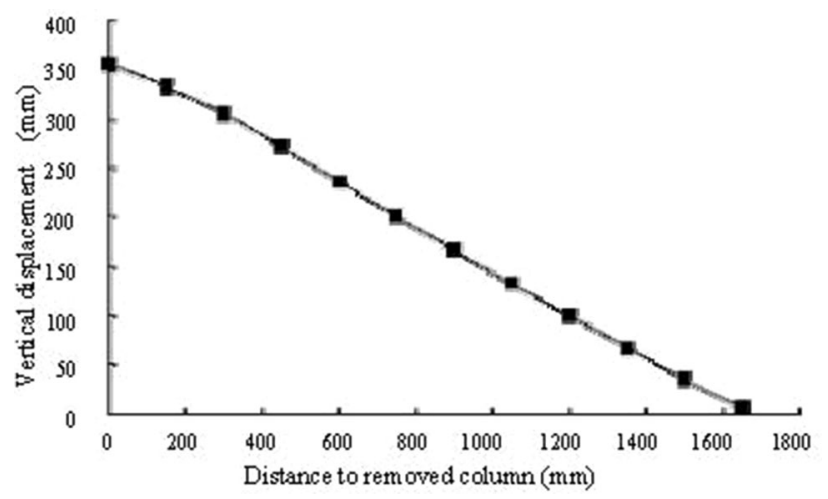

Fig. 12 Vertical displacement of different positions on longitudinal frame beams at collapse limit state.

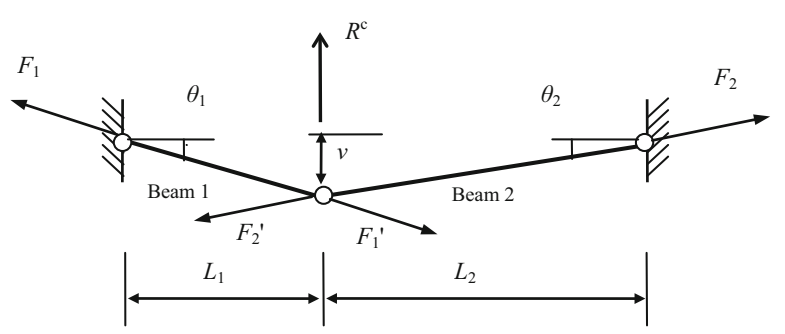

Fig. 13 Schematic diagram of catenary mechanism of beams.

proposed as shown in Fig. 13. The progressive collapse resistance of frame beams was obtained as (Hou and Yang 2014) 


$$
P_{\mathrm{ub}}=\frac{\left(L_{1}+L_{2}\right) v_{\mathrm{u}}}{L_{1} L_{2}} \cdot\left(A_{\mathrm{th}}\right) f_{\mathrm{y}}
$$

where $L_{1}$ and $L_{2}$ are the spans of beam 1 and beam 2, respectively, $v_{u}$ is the vertical displacement of the removed column, $A_{\text {th }}$ is the area of steel bars through whole span, and $f_{y}$ is the yield stress of the steel bars in frame beams. The model was originally proposed by Li et al. (2011), and the reliability was verified by Hou and Yang (2014).

\subsection{Tensile Membrane of Slabs}

Based on the failure phenomenon as shown in Fig. 6, the internal area of the frame slabs surrounded by the negative moment yield lines is viewed as an analysis object, and its boundaries are assumed to be rectangular. Thus, the model of the progressive collapse resistance of frame slabs is proposed as shown in Fig. 14. Based on the analysis of the progressive collapse process, just the effect of the longitudinal direction of the frame slabs on the progressive collapse resistance of the whole structure was considered, and the moments of resistance at the plastic hinge lines in the frame slabs can be ignored at the collapse limit state. Therefore, the boundaries of the analysis object can only bear a pulling force, as shown in Fig. 14. Let $l_{y}$ (the side lengths of slabs (1) and (2) in the direction of the $\mathrm{Y}$ axis) be equal to the projection lengths of the positive moment yield lines in the corresponding position, it can be noted that the load-carrying capacity of the curved boundaries in Fig. 6 and the rectangular boundaries in Fig. 14 are equivalent.

In Fig. 6, for slab BOK, based on the vertical displacement of different positions on the longitudinal frame beams at the collapse limit state (Fig. 12) and the compatibility of deformation between frame beams and slabs, it can be found that the slab edge BK is still straight at the collapse limit state. Figure 15 displays the vertical displacement of different positions in the transverse span centers of slabs at the collapse limit state, which was obtained from the numerical results. It was observed that there was relatively little change in the vertical displacement in the Section OA1 range compared to Section OA2. Therefore, the line section OA1 can approximately be assumed to be straight. Thus, we assumed that the slabs GJK and HIK (Fig. 14), surrounded by positive and negative moment yield lines and outer edges of slabs, were still in two different planes at the collapse limit state, respectively.

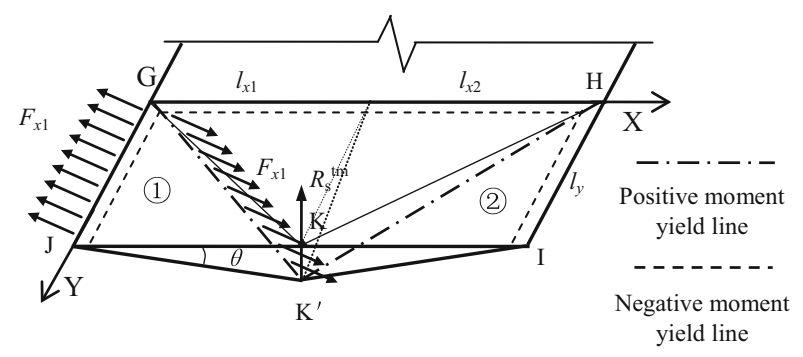

Fig. 14 Analytical diagram for tensile membrane action of frame slabs.

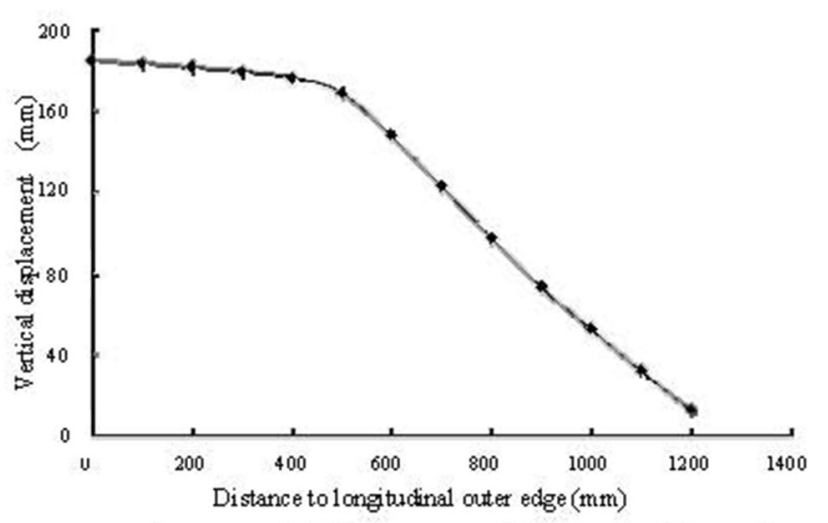

Fig. 15 Vertical displacement of different positions of transverse span centers on frame slabs at collapse limit state.

For slab GJK, based on the vertical equilibrium condition, the progressive collapse resistance can be obtained as:

$$
R_{s G J K}^{t m}=F_{x 1} l_{y} \frac{v}{\sqrt{v^{2}+l_{x 1}^{2}}}
$$

where $F_{x 1}$ is the yield-bearing capacities of steel bars in the range of unit width slab (1); $l_{x 1}$ and $l_{y}$ are equal to the projection lengths of the positive moment yield lines in the corresponding position, respectively; and $v$ is the vertical displacement of Point K.

In the same way, for slab HIK, the progressive collapse resistances can be given as:

$$
R_{s H I K}^{t m}=F_{x 2} l_{y} \frac{v}{\sqrt{v^{2}+l_{x 2}^{2}}}
$$

The progressive collapse resistance of the whole frame slabs, based on the principle of superposition, as shown in Fig. 6, can be expressed as:

$$
P_{u s}=R_{s G J K}^{t m}+R_{s H I K}^{t m}
$$

\subsection{Validation}

Based on analysis and experimental results, it is noted that the limit vertical displacement of the frame structure is controlled by frame beams on the A-axis. Based on the literature (Hou and Yang 2014), the calculated value of the limit vertical displacement of the removed column $\left(v_{u}\right)$ is $356.7 \mathrm{~mm}$. Substituting the value of $v_{u}$, the geometric dimensions and the properties of steel bars of the frame beams on the A-axis into Eq. (1), the progressive collapse resistance of frame beams $\left(P_{\mathrm{ub}}\right)$ can be calculated $41.5 \mathrm{kN}$.

Based on the deformation compatibility condition of the frame beams and slabs, the limit vertical displacement of Point $\mathrm{K}(v)$ is equal to the limit vertical displacement of the removed column $\left(v_{u}\right)$. Therefore, the value of $v$ should be $356.7 \mathrm{~mm}$. Substituting the value of $v$, the geometric dimensions and the properties of steel bars of the frame slabs into Eqs. (2), (3) and (4), the progressive collapse resistance of frame slabs is $14.9 \mathrm{kN}$.

By using the principle of superposition, the progressive collapse resistance of the whole frame structure is $56.4 \mathrm{kN}$. 
The calculated value is $7.1 \%$ smaller than the experimental result. Portions of the steel bars have entered the hardening stage in the collapse limit state, but steel hardening is not considered in the model. Thus, the progressive collapse resistance obtained from the model is somewhat conservative. Moreover, it can be found that the progressive collapse resistance of frame slabs is $26.4 \%$ of the progressive collapse resistance of the whole frame structure.

\section{Conclusion}

A static test and finite element analysis to assess the progressive collapse resistance of an $\mathrm{RC}$ frame mechanism after a side column loss are described. The progressive collapse process of the structure can be sectioned into four stages, based on the experimental and computational results, which are the elastic stage, the elastoplastic stage, the plastic stage and the composite stage of catenary action and tensile membrane action.

The progressive collapse of the structure occurs only in the bay where the removal side column is located. Also, due to the lack of lateral support or constraint, the transverse frame beam and the transverse direction of the frame slabs in the collapse area almost entirely failed in the collapse limit state. Greater catenary action and tensile membrane action are respectively mobilized in the longitudinal frame beams and the longitudinal direction of the frame slabs.

Based on the computational and experimental results, a simplified model of the progressive collapse resistance of a $\mathrm{RC}$ frame after a side column is removed was proposed in which frame beams and slabs are taken as the catenary mechanism and tensile membrane mechanism, respectively. In the catenary mechanism, the axes of the longitudinal frame beams can be taken as straight. For the tensile membrane mechanism, the internal area of the frame slabs surrounded by the negative moment yield lines can be viewed as an analysis object, and its two areas of progressive collapse resistance were still in two different planes at the collapse limit state.

\section{Acknowledgments}

This work was supported by the National Natural Science Foundation of China (Grant No. 51208421 and 51378506).

\section{Open Access}

This article is distributed under the terms of the Creative Commons Attribution 4.0 International License (http://creativecommons.org/licenses/by/4.0/), which permits unrestricted use, distribution, and reproduction in any medium, provided you give appropriate credit to the original author(s) and the source, provide a link to the Creative Commons license, and indicate if changes were made.

\section{References}

American Society of Civil Engineers (ASCE). (2010). Minimum design loads for buildings and other structures. SEI/ASCE 7-10. Reston, VA: American Society of Civil Engineers.

Brunesi, E., \& Nascimbene, R. (2014). Extreme response of reinforced concrete buildings through fiber force-based finite element analysis. Engineering Structures, 69, 206-215.

Brunesi, E., Nascimbene, R., Parisi, F., \& Augenti, N. (2015). Progressive collapse fragility of reinforced concrete framed structures through incremental dynamic analysis. Engineering Structures, 104, 65-79.

Choi, H., \& Kim, J. (2011). Progressive collapse-resisting capacity of reinforced concrete beam-column subassemblage. Magazine of Concrete Research, 63(4), 297-310.

Department of Defense (DoD). (2009). Unified facilities criteria, design of buildings to resist progressive collapse. Washington DC: Department of Defense.

GB50010-2010. (2010). Code for design of concrete structures. Beijing, China: National Standard of the People's Republic of China.

GB50011-2010. (2010). Code for seismic design of buildings. Beijing, China: National Standard of the People's Republic of China.

General Services Administration (GSA). (2013). Alternate path analysis and design guidelines for progressive collapse resistance. Washington DC: General Services Administration.

Hallquist, J. (2007). LS-DYNA keyword user's manual. Livermore: Livermore Software Technology Corporation. Version 971.

Hou, J., \& Yang, Z. (2014). Simplified models of progressive collapse response and progressive collapse-resisting capacity curve of RC beam-column sub-structures. Journal of Performance of Constructed Facilities, 28, 04014008. doi:10.1061/(ASCE)CF.1943-5509.0000492.

Izzuddin, B. A., Vlassis, A. G., Elghazouli, A. Y., \& Nethercot, D. A. (2008). Progressive collapse of multi-storey buildings due to sudden column loss - part I: Simplified assessment framework. Engineering Structures, 30, 1308-1318.

Kang, S. B., Tan, K. H., \& Yang, E. H. (2015). Progressive collapse resistance of precast beam-column sub-assemblages with engineered cementitious composites. Engineering Structures, 98(1), 186-200.

Kim, J., \& Choi, H. (2015). Monotonic loading tests of RC beam-column subassemblage strengthened to prevent progressive collapse. International Journal of Concrete Structures and Materials, 9(4), 401-413.

Li, Y., Lu, X. Z., Guan, H., \& Ye, L. P. (2011). An improved tie force method for progressive collapse resistance design of reinforced concrete frame structures. Engineering Structures, 33, 2931-2942.

Málaga-Chuquitaype, C., Elghazouli, A. Y., \& Enache, R. (2016). Contribution of secondary frames to the mitigation of collapse in steel buildings subjected to extreme loads. Structure and Infrastructure Engineering, 12(1), 45-60. 
Mehrdad, S., Andre, W., \& Ali, K. (2011). Bar fracture modeling in progressive collapse analysis of reinforced concrete structures. Engineering Structures, 33, 401-409.

Mehrdad, S., Marlon, B., \& Serkan, S. (2007). Experimental and analytical progressive collapse evaluation of actual reinforced concrete structure. ACI Structural Journal, 104(6), 731-739.

Pachenari, A., \& Keramati, A. (2014). Progressive collapsed zone extent estimation in two-way slab floors by yield line analysis. Magazine of Concrete Research, 66(13), 685-696.

Pham, X. D., \& Tan, K. H. (2013a). Experimental study of beam-slab substructures subjected to a penultimate-internal column loss. Engineering Structures, 55, 2-15.

Pham, X. D., \& Tan, K. H. (2013b). Membrane actions of RC slabs in mitigating progressive collapse of building structures. Engineering Structures, 55, 107-115.

Qian, K., Li, B., \& Ma, J. X. (2015). Load carrying mechanism to resist progressive collapse of RC buildings. ASCE Journal of Structural Engineering, 141(2), 04014107.
Sadek, F., Main, J. A., Lew, H. S., \& Bao, Y. H. (2011). Testing and analysis of steel and concrete beam-column assemblies under a column removal scenario. ASCE Journal of Structural Engineering, 137(9), 881-892.

Shi, Y. C., \& Li, Z. X. (2009). Bond slip modelling and its effect on numerical analysis of blast-induced responses of $\mathrm{RC}$ columns. Structural Engineering and Mechanics, 32(2), 251-267.

Su, Y. P., Tian, Y., \& Song, X. S. (2009). Progressive collapse resistance of axially-restrained frame beams. ACI Structural Journal, 106(5), 600-607.

Yi, W. J., He, Q. F., Xiao, Y., \& Kunnath, S. K. (2008). Experimental study on progressive collapse-resistant behavior of reinforced concrete frame structures. $A C I$ Structural Journal, 105(4), 433-439. 